\title{
Perder el objeto y ganar el proceso: el pensamiento filosófico de Jesús Martín Barbero en la comunicación y la cultura
}

\section{Amparo Marroquín Parducci}

Doctora; Universidad Centroamericana José Simeón Cañas, La Libertad, El Salvador amarroquin@uca.edu.sv

\section{Resumen}

Este artículo indaga el pensamiento filosófico que configuró el análisis de Jesús Martín Barbero sobre la comunicación y la cultura. En sus aportes, es posible encontrar rastros de una filosofía que piensa en la modernidad, pero desde la cultura popular y desde las mediaciones que produce la cultura masiva. El presente texto propone cinco desplazamientos claves del pensamiento académico de la época: el dialógico, el decolonizador, el disciplinario, el metodológico y el ontológico. Su formación en filosofía, que inicia en Ávila y continúa en la Universidad de Lovaina, le da otra visión de las preguntas que se habían realizado en América Latina.

\section{Palabras clave}

Jesús Martín Barbero. Comunicación. Cultura. Filosofía. Cultura popular.

\section{Introducción}

Los caballos que me llevan me han conducido a donde deseaba mi corazón. Poco importa dónde empiece pues volveré aquí. No nos queda más que un camino por recorrer.

Parménides

El tema que desarrollo en este texto se constituye a partir de los planteamientos de un pensador latinoamericano: Jesús Martín Barbero. Filósofo y antropólogo con estudios disciplinares en Ávila, Lovaina y la escuela de Altos Estudios en París, y teórico de la comunicación por su lugar de enunciación, sobre todo a partir de la década de 1970. De 
acuerdo a los trabajos más cuantitativos, Martín Barbero es uno de los teóricos de la comunicación más citados en América Latina1. Su libro De los medios a las mediaciones, publicado por primera vez en 1987 (MARTÍN BARBERO, 1998b), se mantiene como un referente obligatorio para quienes quieren pensar en la comunicación como un proceso cultural y simbólico. Sin embargo, el pensamiento de Martín Barbero no puede ser entendido por fuera de la tradición filosófica en la que se encuentra.

Esta tradición permitió a Martín Barbero cinco desplazamientos desde la filosofía tradicional que son los que elaboro a lo largo de este trabajo: el dialógico a través del cual construyó un saber colectivo-comunitario, más allá de las disciplinas; el decolonizador, que se evidencia en su decisión de situar su pensamiento desde América Latina para observar desde ahí y desde ese lugar dejarse interrogar; un desplazamiento disciplinario, que lo lleva a pensar desde un lugar fronterizo que cruza la filosofía, la comunicación, la antropología, la semiótica y hasta la teología; un desplazamiento metodológico, hijo de esa propuesta genealógica que viene desde Nietzsche (2000) y Foucault (2008); y un desplazamiento ontológico, que le permitió ocuparse del otro y de su lugar en el colectivo, el otro indígena, mestizo, pobre, popular, masivo.

Esta cartografía busca indigar ese pensamiento filosófico que lo configuró y encontrar, en sus aportes, rastros de una filosofía que permita que su pensamiento contribuya como lo ha hecho. No se trata de caer en clasificaciones fáciles y de situar a un pensador exclusivamente en un campo particular del saber. No se quiere caer en la visión ingenua de la defensa a ultranza de una disciplina. De hecho, el presente trabajo me permite afirmar que Martín Barbero pertenece, más bien, al conjunto de pensadores que se resiste a una clasificación. A él le preocupa pensar desde la realidad, desde lo que está aconteciendo, lo que se está moviendo, desde los procesos cambiantes que nos interrogan y que a su vez lo llevan a cuestionar las certezas establecidas. Entre los comunicadores es un filósofo, entre los filósofos es un antropólogo, entre los culturalistas echa mano de su anclaje en la comunicación.

Lo que él llamará su "retorno a la tribu", a la filosofía, se encontrará marcado por una reflexión que se constituye crítica de la razón arrogante y moderna sin renunciar a la

\footnotetext{
${ }^{1}$ Ya en su tesis doctoral de 1989, Carlos Gómez-Palacio elaboró una lista de los autores más influyentes en la investigación latinoamericana de esta disciplina y en ella, Martín Barbero apareció como uno de los diez primeros autores (GÓMEZPALACIO, 1989, p. 162). Y veintiocho años después, en 2017, Rafael Grohman, de la Universidad de Sao Paolo, analiza tesis doctorales y de maestría sobre recepción y encuentra que Jesús Martín Barbero, es el autor más citado de su corpus analizado (GROHMAN, 2017, p. 47).
} 
posibilidad política de la utopía. Y esto, es a mi parecer, la parte de su pensamiento que menos se ha revisado. Martín Barbero produce un pensamiento de hondura filosófica, y que puede ser mejor entendido en la medida en que recuperamos esos diálogos de los que a veces quedan pocas huellas.

De los medios a las mediaciones nos da ya una pista, en su introducción, Martín Barbero (1998a, p. xi) dice: “[...] venía yo de la filosofía, y de la heideggereana morada del ser di con mis huesos en la choza-favela de los hombres, construida en barro y caña, pero con radio transistores y antenas de televisión [...]”. Con esas palabras comenzó un diálogo que todavía hoy convoca reflexiones y preguntas nuevas. Venía de la filosofía, venía de la metafísica, venía de Occidente, venía del sueño de la razón, del pensamiento formal, de la lógica, de la filosofía de la ciencia, de la Grecia que pensó casi todo el pensamiento con el que pensamos. Pero también venía de otros lugares, más bastardos, que de a poquito le hacían rendijas a su heideggereana morada. Porque Jesús Martín Barbero también venía del mundo popular, de las memorias de su madre, de la religiosidad de la gente sencilla que cree y ayuda a los que puedan, de una dictadura que en un solo gesto silenciaba y hacía nacer múltiples y pequeñas formas cotidianas de resistencia. Venía, como dirá el nicaragüense Sergio Ramírez,

[...] de Cortázar y Frantz Fanon, del Che y Janis Joplin, Martin Luther King y los Beatles, los Rolling Stones, Lumumba y Bob Dylan, y de Woodstock, ese campo que era una batalla tan grande como la de la cordillera de los Andes, Argelia y el Congo, las calles de París en mayo y la plaza de Tlatelolco en octubre de 1968. (RAMÍREZ, 2013, doc. no paginado).

Y llegó a Colombia, la que desde hace tanto tiempo juega con las palabras, la que escribe poemas y realismos mágicos. La Colombia de la larguísima época de la violencia, la Colombia de Camilo Torres y de Fals Borda, la de un Medellín donde una iglesia particularmente osada dio un giro que miraba justo hacia las mediaciones y en donde los obispos reconocieron que los medios "[...] forjan una nueva cultura, producto de la civilización audiovisual que, si por un lado tiende a masificar al hombre, por otro favorece su personalización." (CONSEJO EPISCOPAL LATINOAMERICANO, 2014, p. 205). Fue desde ahí que, con la paciencia de un coleccionista recolectó sucesos y asombros. Y con la habilidad de un artesano construyó algunos textos que ahora son ya referencia obligada. 


\section{El desplazamiento hacia un pensamiento dialógico}

Muchos textos académicos caen en la tentación de producir monólogos, de conversar exclusivamente con quien refuerza el punto de vista del autor. El derecho a disentir, en la época de las redes sociales, se diluye en medio de la cantidad de me gusta. El pensamiento de Martín Barbero, más que una expulsión de lo distinto (HAN, 2017) plantea una ética de la escucha. De múltiples diálogos. Las reflexiones sobre comunicación y cultura, no habrían sido posibles sin los seminarios de Consejo Latinoamericano de Ciencias Sociales (CLACSO), sin los debates de Federación Latinoamericana de Facultades de Comunicación Social (FELAFACS) y sin las investigaciones que muchos académicos más hacían en Asociación Latinoamericana de Investigadores de la Comunicación (ALAIC). Desde siempre, Martín Barbero acogió voces muy diversas, y no con una pretensión erudita, sino con la urgencia que tiene alguien que busca respuestas.

El diálogo empezó desde muy joven. Se dejó desplazar por las preguntas de otros. Cuando llegó por primera vez a Colombia en octubre de 1963, descubrió que, aunque el idioma era el mismo, las formas de habla eran completamente distintas y reaccionó asombrado cuando la chica que le llevaba el desayuno le preguntó: “¿le provoca un perico?”. Y tardó en descubrir que en realidad lo que ella quería saber era si tomaría café.

Tres diálogos van a configurar el origen de sus preguntas: primero, el de su infancia. La figura de la madre, que le enseña a leer a través de la poesía bucólica y popular de José María Gabriel y Galán, va a implicar para Martín Barbero el aprendizaje de muchos gestos de la cultura popular, la generosidad, el bueno humor, la religiosidad y la sencillez. Posteriormente, su profesor de filosofía de la cultura, Alfonso Querejazu, un cura boliviano que había sido diplomático y que le permitió tener las primeras discusiones de cultura y filosofía en un tiempo en que la dictadura de Franco permitía muy poca reflexión crítica.

Un segundo diálogo fundamental, será el que construye desde sus estudios del doctorado en filosofía, en Lovaina, que van de 1969 a 1972. Durante este tiempo, con los ecos del mayo de París, Jesús Martín Barbero elaboró su tesis doctoral. La tituló La palabra y la acción, dirigida por Jean Ladrière (MARTÍN BARBERO, 1972). El trabajo puso a dialogar a dos teóricos contemporáneos: Paul Ricoeur, que aportaba la discusión sobre la palabra y que a su vez aperturaba a un diálogo filosófico con otros pensadores preocupados por la narratividad, el tiempo, la memoria y Paulo Freire, el pedagogo latinoamericano que se identificaba con la acción, con la praxis. El objetivo final de Martín Barbero (1972) era 
descubrir en qué momento la palabra se vuelve acción. Su respuesta final es que hay tres grandes momentos para ello: la profecía, el mito y la poesía, cuando los usamos, ponemos en juego el dispositivo de autoimplicación que la lengua nos permite.

El tercer diálogo es posterior, pero es también profundamente revelador: Walter Benjamin:

\begin{abstract}
Si hay amores a primera vista, o más a lo intelectual, parentescos espirituales, eso fue lo que sentí a través de la lectura de ese libro, y en especial de uno de sus textos, L'auteur comme producteur. Trabajaba yo entonces sobre las transformaciones del marxismo que venían tanto del "oriente" como del "occidente" -Adam Schaff, Karel Kosik, Althusser, Lucien Goldmann- y en el texto de Benjamin descubrí otro marxismo, el más otro de todos. El primero que osó afirmar: "en lugar de preguntarse cuál es el lugar de una obra frente a las relaciones de producción de una época [...] yo quiero proponeros otra pregunta: ¿cuál es su lugar en esas relaciones?". El desplazamiento de la mirada crítica que introducía W. Benjamin era de ciento ochenta grados, del afuera al adentro, de la posición a la escritura, de lo que la obra dice acerca de las relaciones de producción a los procesos internos de construcción de la obra, y su específica función en la transformación de esas relaciones. ¡Y eso dicho en el año 34! (MARTíN BARBERO, 2000, p. 11-12).
\end{abstract}

Si en lugar de abrirse a estos diálogos y a los posteriores, hubiera destacado estas propuestas por demasiado otras, su pensamiento no se habría movido. Por eso, el asombro frente al pensamiento de otros se mantuvo como una constante. Desde tesis de estudiantes y discusiones de clases, hasta reflexiones de los clásicos de las ciencias sociales y de la filosofía, Martín Barbero puso todo eso junto para preguntarse por lo que implican los medios, no para las industrias, que ya algo sabíamos, sino para la vida cotidiana de las personas que, a las siete de la tarde, encienden la televisión y se reúnen en torno a la telenovela. El pensamiento dialógico que heredó de una filosofía como la de Ricoeur, Freire y Benjamin le permitió ir hacia los otros.

\title{
3 El desplazamiento del lugar de enunciación o la decolonización de la mirada
}

Bogotá desde lejos, arrancada a mi vida y llorándote dentro [...] sabiéndote conmigo y contra mí. (MARTÍN BARBERO, 1969, p. 32). 
No es necesario elaborar demasiado este desplazamiento. Martín Barbero se constituyó un filósofo que decidió no pensar desde la centralidad de occidente. Con un gesto de distancia, desplazó la reflexión de Europa hasta América Latina, de Ricoeur a Freire. De Barthes a Eliseo Verón. De la palabra a la acción. El mapa geográfico le permitió confirmar que en la cultura popular había formas estéticas que no cabían en la razón tradicional e ilustrada. Había unas formas de resistencia que se situaban en otro lugar. Que había que desplazar los grandes relatos de la modernidad, para comprender esas contradictorias utopías políticas latinoamericanas en donde convivían hace un tiempo el marxismo y la religiosidad, en donde habitábamos a un tiempo la premodernidad más rígida, la modernización acelerada y la galopante y suspicaz postmodernidad. Llegó a Colombia por primera vez en 1963 y volvió después de su doctorado, en 1972.

Colombia fue América Latina, fue el lugar de la periferia que le permitía cuestionar las certezas de las academias hegemónicas. Antes que la decolonización fuera nombrada como una urgencia, la comunicación se encontró con un grupo de entusiastas pensadores latinoamericanos que buscaban pensar desde un lugar-otro. Por eso transitó casi un año por Puerto Rico, luego tres años en México, y continuó su viaje por muchos países, escuchó, preguntó, anotó. Y eso le permitió también hacer preguntas que otros no hacían, mover el lugar de las preguntas, interrogar por los usos, por los caminos desde los que se hacen los sentidos, pensar en los sujetos y no solo en las tecnologías, pensar en las mediaciones. El lugar que se decide que sea de enunciación es, también, un gesto político, porque es una opción pensar desde la tierra de Camilo Torres y Fals Borda. Pensar desde la violencia, desde la precariedad, desde un lugar que produce estructuras de lo terrible.

\section{El desplazamiento disciplinario}

Ya lo he mencionado, pero me interesa destacarlo, así sea de manera breve. El pensamiento de Martín Barbero nos ha interrogado al revés. Para los comunicadores pregunta desde la filosofía, para los filósofos desde la antropología, para los antropólogos desde la comunicación. Pero más todavía: el lugar de enunciación se ha movido en su trabajo de ese espectro que apostaba por la filosofía especulativa para colocarse en el camino más hermenéutico, más genealogista (más bastardo, de nuevo) puesto que se pregunta por los insospechados orígenes con los que hemos nombrado tantas categorías que pensábamos claras: lo popular, lo masivo, la hegemonía, los medios, las mediaciones. 
Para poder plantearnos nuevas preguntas sobre la comunicación necesitamos el extrañamiento de la mirada, y una manera de conseguir ese extrañamiento es a través de una adscripción disciplinaria que se abre a la realidad, que se deja tocar por ella, que reconoce que no tiene todas las respuestas. Esto es lo que sucede en su bien conocida "ruptura epistemológica" a raíz de la película La ley del monte en un cine de Cali. Quizá una de las influencias más notables para la apertura de su pensamiento a esta posibilidad le viene dada de Theodor Adorno. Ya en distintos espacios, Martín Barbero ha señalado la gran influencia que este pensador tuvo, en su pensamiento. En particular, una cierta concreción del concepto de "dialéctica negativa" (ADORNO, 2005). No se trata de construir una enunciación nueva positiva, sino de colocar dos opuestos y develar la contradicción que en sí mismos implican. Ese es el trabajo de su primer libro sistemático: Comunicación masiva, discurso y poder, en el que llega a preguntarse si lo que afirma en el resto de su reflexión puede ponerse en duda:

[...] lo que se intenta en esta parte es una reflexión en negativo de lo que parcialmente, solo parcialmente, el resto de este libro intentará plantear en positivo. Su razón es que ha sido a partir de, y luchando con las contradicciones, que la reflexión crítica latinoamericana vive. Por eso, más que una crítica, de lo que se trata en verdad es de una autocrítica. (MARTÍN BARBERO, 1978, p. 33).

\section{El desplazamiento metodológico o el mapa nocturno}

Martín Barbero recupera una metodología filosófica que enuncia ya en la figura de Saint Exupéry del mapa nocturno. No se trata de construir una nueva verdad universal, absoluta, sin grietas, metafísca. Se trata de una verdad que se consigue en sucesivas aproximaciones, en un mapa nocturno. Un mapa que coloca el acento epistemológico en el devenir diacrónico. Para ello, el método filosófico de la genealogía se le vuelve fundamental.

La genealogía, en su sentido etimológico, remite al origen y las procedencias de algo. Sin embargo, como método filosófico es relativamente reciente; empezó a ser trabajado por Nietzsche (1996) en obras como Humano, demasiado humano, y se constituye como tal en el libro de Nietzsche (2000), Genealogía de la moral. Aunque se ha sostenido en distintos momentos que la obra de Nietzsche no pasó de ser una tentativa de ensayo, que es formalmente fragmentaria y que "La obra capital sistemática quedó sin realizar [...]" 
(ROMERO, 2001, p. 2), es posible encontrar en sus textos una interpretación del sentido de los conceptos morales y el origen de estos.

La genealogía es inicio y nacimiento, pero también permite trazar la diferencia o la distancia respecto del origen. Basado en este concepto y en la deconstrucción heideggeriana de la metafísica, en una primera etapa de su trabajo, Foucault (1988) propuso otro camino: el de arqueología, que no debe confundirse con el primero, y que se refiere al descubrimiento y análisis de los supuestos o a priori históricos de una época determinada, que condicionan otras manifestaciones. Posteriormente, Foucault (2008) transitará hacia un método genealógico, dado que la genealogía le permitirá un primer paso hacia el análisis del poder.

¿Por qué afirmar que Jesús Martín Barbero hace una genealogía cuando él mismo no lo señala de esta manera? De los medios a las mediaciones, que es donde lo aplica de manera más evidente, parte de buscar los "insospechados orígenes" de los que habla Foucault (2008), pero también esa "proliferación de acontecimientos" con y contra los que se ha formado la categoría de lo popular y lo masivo. En el inicio de su libro, Martín Barbero (1998b, p. 2) lo deja ya enunciado: "Hacer historia de los procesos implica hacer historia de las categorías en que los analizamos y los nombramos.". La decisión de situar de manera histórica los conceptos implica una toma de distancia con las certezas metafísicas. Nos devuelve al mapa nocturno, a la dialéctica negativa, al diálogo.

\section{El desplazamiento ontológico o el lugar del otro.}

No se nos ha dado la esperanza, sino es por los desesperanzados. Walter Benjamin (1996)

Desde muy joven, Martín Barbero se opuso al pensamiento metafísico habitado de certezas y con pretensiones universales que le resultaban particularmente sospechosas en un tiempo en donde las formas de nombrar el mundo cambiaban muy rápidamente. Sin embargo, a pesar de sus propias críticas, su pensamiento se ancló en la razón moderna, utópica, capaz de cargar y hacerse cargo de la humanidad, pero ya no solamente desde esa mirada a un nosotros-occidental-masculino-blanco y europeo, pensar lo popular situado desde América Latina le implicó inclinarse a pensar en el lugar del otro y de la cultura 
popular. ¿Dónde existe? ¿En qué coordenadas del tiempo-espacios está anclada? ¿Cuál es su sensibilidad?

Jesús Martín Barbero transitó de una razón apathica hacia esa preocupación que Levinas nombró tan claramente y que en este caso se presentaría como ir al encuentro del sensorium del otro. Es hacerse cargo y cargar, es contar (historias) y ser tomado en cuenta (ser visto). Es colocar al centro de la reflexión una cultura popular que es -al otro lado de su espejo- una cultura masiva, light, seriada, hija del mercado, pero que siempre será fiesta, carnaval, risa, música que se sale de tantos cánones, por más que intenten mantenerla en su sitio a través de políticas, gestiones, intervenciones y demás estrategias. Es entender que lo que la comunicación actual produce desde sus tecnologías, funciona porque el melodrama, como matriz cultural y formato, se coloca al centro de la ficción y desde ahí nos encontramos en ese universo de lo conservador y lo rebelde, de la espontaneidad y la lealtad, del cuerpo y la fantasía, de la imagen y siempre, siempre, siempre, del melodrama.

Una revisión más hermenéutica evidencia que el lenguaje y la experiencia estética son para Martín Barbero el lugar de la enunciación y del acontecimiento. Su reflexión permite una ampliación semántica que visibiliza que en la clase popular hay una estéticaotra.

Es la cultura popular la que reclamaba un análisis propio y la que construye ciertas categorías de pensamiento. Así, el espacio de lo popular, de la poesía bucólica, del melodrama que se evidencia en los géneros de la novela folletín, la radio novela, la telenovela, el cine popular, el periódico amarillista y muchos otros espacios se volverán susceptibles de una aproximación-otra.

La cultura se vuelve objeto de reflexión que funciona a partir de esta triple construcción sobre la praxis: la objetivación o nivel de las estructuras, la comunicación o la cuestión de las mediaciones y la autoimplicación, que evidencia el mito, la profecía, la poesía como formas de aproximación a lo real.

\section{Breves conclusiones o el retorno a la tribu}

Durante las últimas tres décadas, Martín Barbero ha sido uno de los autores más leídos en comunicación. A lo largo de esos años, los departamentos de filosofía, las revistas especializadas y los espacios canónicos no se ocuparon de su pensamiento. La comunicación 
es demasiado indisciplinada, demasiado coyuntural para ser tomada en cuenta por la filosofía mucho más universal, abarcadora, sistémica. Sin embargo, su ejercicio filosófico pasa en ciertos momentos, por un diálogo intencionado con la comunidad profesional que se constituye desde la academia latinoamericana. En este filosofar, traza una agenda que se volverá central en la década de 1990 y de 2000, sus preocupaciones responden a temáticas sobrelas modernidades (MARTÍN BARBERO, 1992) y la problematización de la mirada en relación con la técnica (MARTÍN BARBERO, 2003). Los últimos años, los diálogos con autores como Giacomo Marramao y Jacques Rancière marcan su regreso al lugar inicial de reflexión.

Desde la comunicación, me parece que en algunos momentos nos enfrentamos al riesgo de volver su propuesta un pensamiento único, homogéneo, quizá reducirlo a consignas como "perder el objeto para ganar el proceso", "hay que pasar de los medios a las mediaciones"; "hay que cambiar la mirada, dejar de analizar los contenidos para ver qué hace la gente con lo que ve", podemos olvidar en dónde se ancla, por qué, en su momento, fue molesto para algunos pensadores que vieron en su crítica a la visión cultural del marxismo althusseriano una falta de compromiso político. Siempre existe un peligro en las modas académicas. El peligro de invocar al autor legítimo, no porque veamos que es útil para complejizar nuestro tema, sino únicamente para legitimarnos a nosotros mismos. Cuando este peligro asoma y deslumbra, creo que es bueno volver a la discusión grupal, colectiva, anclada en el contexto que este pensador nos intenta mostrar.

En Centroamérica, Jesús Martín Barbero circuló, como diría Monsiváis (información verbal2 $^{2}$ ), a través "del grado xérox de la escritura". Es decir, en el estilo de los países que están a la periferia de la academia oficial, en fotocopias que nos lo volvían accesible (como circula ahora en múltiples versiones de pdf alojadas en muchísimas páginas web). Y desde sus reflexiones, en Guatemala, El Salvador, Nicaragua, Honduras aprendimos (a veces solo repetíamos), pero a veces conseguíamos hacer preguntas nuevas. ¿Cómo nombrar nuestras propias estructuras de lo terrible? ¿Cómo nombrar las guerras que se vivían, los muertos que nos amanecían y que seguimos cargando? ¿Cómo nombrar la paz que empezamos a soñar, los jóvenes orillados de nuevo a otras violencias, expulsados, corriendo tras el tren de la muerte, enfrentados a los Zetas? En Centroamérica aprendimos gracias a este diálogo (que nos abría la puerta a un diálogo más grande con América Latina) que somos mestizaje,

${ }^{2}$ Comunicación personal de Carlos Mosiváis con la autora en una conferencia en 9 de mayo de 2001. 
hibridación. Que el reino de la contradicción es el reino que habitamos. Y que la realidad no se nos presenta de forma transparente, no quiere ser aprendida. "Como los ojos del murciélago [...]”, dijo Aristóteles (1975, libro 2), “[...] somos ciegos a lo más luminoso, a lo más evidente.". Tuvimos que pasar muchos diálogos y vivir tantos acontecimientos para entender que no somos solo alienación o solo resistencias. Somos al mismo tiempo gozo y sueños, escapes de la realidad y resistencias cotidianas.

Todavía es posible, entonces, no repetir, sino retomar sus desplazamientos, establecer construcciones dialógicas de conocimiento, pensar desde un lugar que no es el centro (desde la periferia, desde la intemperie), desde la (in)disciplina, desde la genealogía que pregunta por insospechados orígenes, desde la pregunta por el popular-otro.

No se trata entonces de quedarnos ahora en un homenaje de palabras bonitas y respuestas sospechosamente cerradas y acabadas, se trata de volver a entender con terquedad y empeño cómo se nos sigue moviendo el mapa de lo conocido hasta quedar irreconocible, se trata de ir, desde nuestro Occidente de narrativas frágiles y política que no se toma la calle, hacia el oriente de ese texto que es la cultura popular. Esa es la pista que en Centroamérica quisiera que consigamos recuperar, esos desplazamientos: que la cultura popular pervive desde unas matrices culturales, desde ciertas ritualidades, y que por debajo de los videojuegos y de game of thrones, de las migraciones masivas y de las violencias, lo popular nos sigue habitando, con una posibilidad política que debemos saber aprovechar. Y a través de la cultura popular se trata, me parece a mí, de volver a encontrar, en esta época de postverdades, de Trump, de desencantos, se trata de volver a encontrar las (nuevas) formas populares de la esperanza.

\section{Referencias}

ADORNO, Theodor. Dialéctica negativa o la jerga de la autenticidad. Madrid: Akal, 2005. ARISTÓTELES. Metafísica. México: Porrúa, 1975.

BENJAMIN, Walter. Dos ensayos sobre Goethe. Barcelona: Gedisa, 1996.

CONSEJO EPISCOPAL LATINOAMERICANO. Las cinco conferencias generales de episcopado latinoamericano. Bogotá, 2014. 
FOUCAULT, Michel. Arqueología del saber. México: Siglo XXI, 1988.

FOUCAULT, Michel. Nietzsche, la genealogía, la historia. Valencia: Pre-textos, 2008.

GÓMEZ-PALACIO, Carlos. The origins and growth of mass communication research in Latin America. 1989. Thesis (Doctor of Philosophy) - Stanford University, Palo Alto, 1989.

GROHMAN, Rafael. Does social class still matter? An analysis of $\mathrm{PhD}$ and master thesis (2010-2014). Contracampo, Niterói, v. 36, n. 1, p. 42-60, abr./jun. 2017.

HAN, Byung-Chul. La expulsión de lo distinto. Barcelona: Herder, 2017.

MARTÍN BARBERO, Jesús. Arte y palabra. Universidad y mundo, n. 6, abr. 1969.

MARTÍN BARBERO, Jesús. Comunicación masiva: discurso y poder. Quito: Ciespal, 1978.

MARTÍN BARBERO, Jesús. De los medios a las mediaciones: comunicación, cultura y hegemonía. Bogotá: Convenio Andrés Bello, 1998b.

MARTÍN BARBERO, Jesús. Estética de los medios audiovisuales. In: XIRAU, Ramón; SOBREVILA, David (Ed.). Estética. Madrid: Trotta, 2003. p. 303-328.

MARTÍN BARBERO, Jesús. La palabra y la acción: por una dialéctica de la liberación. 1972. Tesis (Doctorado en Filosofía) - Universidad de Lovaina, Lovaina, 1972.

MARTÍN BARBERO, Jesús. Mis encuentros con Walter Benjamin. In: MARTÍN BARBERO, Jesús; HERLINGHAUS, Hermann (Org.). Contemporaneidad latinoamericana y análisis cultural: conversaciones al encuentro de Walter Benjamin. Madrid: Iberoamericana Vervuert, 2000.

MARTÍN BARBERO, Jesús. Modernidad, postmodernidad, modernidades: discursos sobre la crisis y la diferencia. Praxis Filosófica, Cali, n. 2, p. 37-59, marzo 1992.

MARTÍN BARBERO, Jesús. Pistas para entre-ver medios y mediaciones. In: MARTÍN BARBERO, Jesús. De los medios a las mediaciones: comunicación, cultura y hegemonía. 5. ed. Bogotá: Convenio Andrés Bello, 1998a. p. xi-xxii.

NIETZSCHE, Friedrich. Humano, demasiado humano. Madrid: Akal, 1996.

NIETZSCHE, Friedrich. Genealogía de la moral. Madrid: Edaf, 2000.

RAMÍREZ, Sergio. No me arrepiento de la revolución, más allá del desengaño. El Clarín, Buenos Aires, 13 jul. 2013.

ROMERO, José. El caos y las formas: experiencia, conocimiento y verdad en F. Nietzsche. Comares: Granada, 2001. 
To lose the object and to win the process: the philosophical thought of Jesús Martín Barbero in communication and culture

\begin{abstract}
This article traces the philosophical thought that shaped Jesús Martín Barbero's analysis about communication and culture. In his contributions, it is possible to find vestiges of a philosophy that addresses modernity, from the popular culture and the mediations produced by the massive culture. This text points out five key displacements of the academic thought of his time: the dialogical, the decolonizing, the disciplinary, the methodological and the ontological. With his degree in Philosophy that started in Ávila and continued at the University of Louvain he was allowed to have a new vision at the questions that were made in Latin America.
\end{abstract}

\title{
Keywords
}

Jesús Martín Barbero. Communication. Culture. Philosophy. Popular culture.

\section{Perder o objeto e ganhar o processo: o pensamento filosófico de Jesús Martín Barbero em comunicação e cultura}

\section{Resumo}

Este artigo traça o pensamento filosófico que moldou a análise de Jesus Martín Barbero sobre comunicação e cultura. Em suas contribuições, é possível encontrar vestígios de uma filosofia que pensa na modernidade, desde a cultura popular e as mediações produzidas pela cultura massiva. Este texto propõe cinco deslocamentos fundamentais do pensamento acadêmico de sua época: o dialógico, o descolonizador, o disciplinar, o metodológico e o ontológico. Sua formação em filosofia, que começa em Ávila e continua na Universidade de Lovaina, Ihe dá outra visão sobre as perguntas que haviam sido feitas na América Latina.

\section{Keywords}

Jesús Martín Barbero. Comunicação. Cultura. Filosofia. Cultura popular. 